\title{
Torsion of Appendix Epiploicae as a Cause of Abdominal Pain in Postpartum Period - A Rare Case Report
}

\author{
Rahul Singh', Pooja Singh²
}

\author{
${ }^{1}$ Department of General Surgery, Motilal Nehru Medical College, Prayagraj, Allahabad, Uttar Pradesh, India, \\ ${ }^{2}$ Department of Gynaecology, Raj Nursing Home, Allahabad, Uttar Pradesh, India
}

\begin{abstract}
Torsion of an epiploic appendix is a little or difficult to diagnose initially is a rare surgical entity which is capable of mimicking different pathologies. Less than 200 cases of torsion of appendices epiploicae have been reported in literature. Till date, none in my knowledge has been in postpartum period. We report the first case in gynecological literature of a normal delivery being complicated by this rare entity. We present our experience in a 38-year-old pregnant female patient.
\end{abstract}

Key words: Acute abdomen, diverticulitis, epiploic appendicitis, postpartum, pregnant

\section{INTRODUCTION}

Normal vaginal deliveries are usually considered as a safe procedure and can be conducted as home deliveries outside hospital environment in selected cases. The incidence of intra-abdominal complications is rare. We report a case of torsion of appendices epiploicae complicating the puerperium (postpartum period).

Epiploic appendicitis is generally benign normal pedunculated peritoneal adipose structure located on antimesenteric (serosal) surface of colon. It can be due to ischemia, torsion, and infarction of an epiploic appendage.

Clinical features include non-specific symptoms of abdominal pain and leukocytosis, and pre-operative diagnosis

\begin{tabular}{|l|l|}
\hline \multicolumn{2}{|c|}{ Access this article online } \\
\hline \multicolumn{1}{|c|}{ Publisher } & \multicolumn{1}{|l}{ Website: } \\
www.ijdms.in \\
DOl: 10.30954/IJDMS.1.2019.5
\end{tabular}

is rare. It is more common to arrive to a pre-operative diagnosis of appendicitis or diverticulitis.

\section{CASE REPORT}

A 28-year-old pregnant female, third gravida, parity with one previous normal delivery, and history of appendicectomy, was admitted for routine obstetric care at term. Her antenatal period was event free. This child was delivered vaginally, with cephalic presentation. She was shifted to postnatal ward after $6 \mathrm{~h}$ of delivery.

A day later, she complained of sudden onset of epigastric pain, which was non-radiating, with no aggravating or relieving factors. On examination, she was afebrile with a pulse of 90/min and blood pressure of 110/60. Abdomen was soft, non-tender, and no organomegaly. She had nausea, but no vomiting. She was given ranitidine and post-operative analgesia continued.

A day later, she continued to be in pain with nausea being present, she had not passed stool but was passing flatus, she continued to be tachycardic with a pulse rate of $110 / \mathrm{min}$. Abdominal examination revealed that mild distension and bowel sounds were sluggish, but there were no signs

\footnotetext{
Address for Correspondence:

Dr. Rahul Singh, Department of General Surgery, Motilal Nehru Medical College, Prayagraj, Allahabad, Uttar Pradesh, India. E-mail: singhrahul1975@gmail.com
}

Submission: 12 May 2018; Revision: 21 June 2018; Acceptance: 08 July 2018 
of peritonitis. A provisional diagnosis of endometritis was kept, and the patient was investigated. Her hemoglobin was 11.5, WCC - 15,200, neutrophils - 14,000, and C-reactive protein -192 . Other results were within normal limits.

She continued to be symptomatic. Mild tenderness over lower abdomen started appearing; she continued to have tachycardia. The patient was started on intravenous (IV) fluids and IV antibiotics in view of high WCC.

Later, the patient developed increased tenderness, with rising pulse rate. Surgical opinion was taken, X-ray abdomen revealed moderately distended loops of large and small bowel filled with gas, colon visible from cecum to descending colon, but no air was seen in the sigmoid colon or rectum. The patient was continued on IV antibiotics, IV fluids, and close observation. Surgical review was done again; the patient had developed marked rebound tenderness and had signs of peritonitis; the patient was shifted to operating theater; laparotomy was done which revealed torsion of tinea epiploicae, [Figure 1] which was necrosed no other anomaly was found. Abdomen was closed and the patient was sent for routine post-operative care.

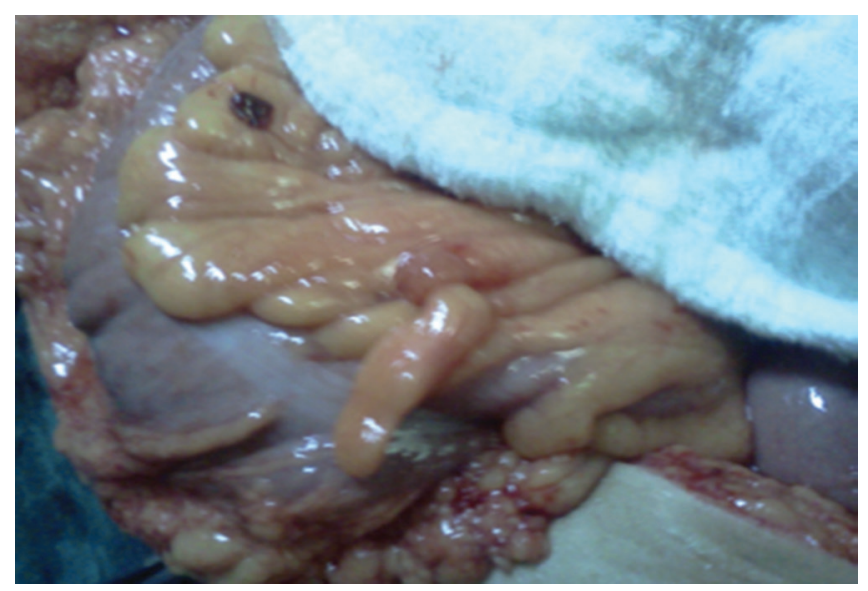

Figure 1: Showing torsion of epiploic appendages

\section{DISCUSSION}

Appendices epiploicae were first reported by Payr, in 1902, covered by visceral peritoneum looks like pedunculated adipose structures protruding from external surface of colon into the peritoneal cavity. About 50-100 appendices epiploicae are normally present; half of them are located anteriorly along with the tinea alba and other adjacent to tenia omentalis on posterolateral border of ascending and descending, and sigmoid colon ${ }^{[1,2]}$ and transverse colon have only single row of appendix epiploicae adjacent to tenia libera as greater omentum attaches to its antimesenteric border.

Usually, these structures are $1-2 \mathrm{~cm}$ thick and $2-5 \mathrm{~cm}$ long but can be up to $15 \mathrm{~cm}^{[3,4]}$
Each epiploic is supplied by two end arteries branching from vasa recta longa of colon and drained by a single tortuous vein this along with the pedunculated shape, and excessive mobility makes the epiploicae rather prone to torsion and ischemia. ${ }^{[5]}$

The function of appendix epiploicae remains unknown, but they are thought to be a protective cushion during peristalsis, provide local defense against infection, and be a site for fat storage.

\section{Pathophysiology and Diseases of Appendices Epiploicae}

Diseases of appendices epiploicae are a rare cause of intraabdominal complications, and a diagnosis preoperatively is rare even in a general surgical unit. The condition is usually mistaken for acute appendicitis and diagnosis reached usually after laparotomy. In a 5-year review between 1993 and 1998[6] by Al-Jaberi et al., only five cases of torsion appendices epiploicae were reported and none of them were diagnosed before surgery. A pre-operative diagnosis on a female in an immediate delivery period becomes all the more challenging.

Diseases of the epiploic appendices are most common in the $3^{\text {rd }}$ and $4^{\text {th }}$ decades of life, although they have been reported in a wide range of ages ranging from 12 to 82 years of age. ${ }^{[7]}$ Men and women are equally affected. ${ }^{[7,8]}$ The right iliac fossa remains the most common site for the pain and tenderness, even if the sigmoid colon is the affected site. Appetite and bowel functions are usually unchanged..$^{[9,10]}$ Nausea and vomiting were reported in $25-40 \%$ of the patients and a palpable RIF mass was reported in a similar percentage, ${ }^{[1-14]}$ there was no palpable mass in our patient.

\section{Radiological Diagnosis}

Under normal circumstances, appendices epiploicae are not visible during plain abdominal radiography fluoroscopy or computerized tomography of abdomen unless they are surrounded by sufficient amount of intraperitoneal contrast material, for example, massive intraperitoneal fluid accumulation or after injection of intraperitoneal dyes, for example, in hysterosalpingography. ${ }^{[1]}$

\section{Disorders of Appendices Epiploicae Include}

- Torsion and necrosis

- Primary and secondary epiploic appendicitis ${ }^{[5]}$

- Herniation

- Lipoma of appendices epiploicae

- Involvement by metastatic disease.

Like any other structures with an end arterial blood supply and mobile pedicle appendices epiploicae are prone to risk of torsion and necrosis. ${ }^{[3-6]}$ An enlarged peritoneal cavity due to 
obesity, ascites, recent delivery, or recent abdominal surgery can be a contributing factor. ${ }^{[1]}$

\section{Management of EA}

- Self-limiting with an average of 10-12 days

- Can be managed surgically (excision of the infarcted epiploic appendix)/laparoscopic appendectomy. Can also be managed conservatively.

\section{CONCLUSION}

Diagnostic laparoscopy is a useful tool for surgeons in assessing abdominal pain where the cause is elusive. It may be used to diagnose and treat torsion of an epiploic appendix effectively. Torsion of appendices epiploicae is a rare entity but can complicate the postpartum period. The diagnosis can be tricky and the disease pathology is usually diagnosed only after laparotomy.

Key features (Imaging):

- Very commonly found on the left side (predominantly sigmoid colon)

- A fatty tag containing oval lesion with a hyperattenuating rim abutting the colonic wall and surrounded by inflammatory changes.

- Central high attenuating area reflecting thrombosed vein.

\section{REFERENCES}

1. Gourgiotis S, Oikonomou C, Veloudis G, Lardou I, Pittaras G, Villias C, et al. The diagnostic dilemma of primary epiploic appendagitis and how to establish a diagnosis. Oman Med J 2016;31:235-7.

2. Almuhanna AF, Alghamdi ZM, Alshammari E. Acute epiploic appendagitis: A rare cause of acute abdomen and a diagnostic dilemma. J Family Community Med 2016;23:48-50.

3. Sand M, Gelos M, Bechara FG, Sand D, Wiese TH, Steinstraesser L, et al. Epiploic appendagitis clinical characteristics of an uncommon surgical diagnosis. BMC Surg 2007;7:11.

4. Choi YU, Choi PW, Park YH, Kim JI, Heo TG, Park JH, et al. Clinical characteristics of primary epiploic appendagitis. J Korean Soc Coloproctol 2011;27:114-21

5. Pogorelić Z, Stipić R, Druzijanić N, Perko Z, Grandić L, Vilović K, et al. Torsion of epiploic appendage mimic acute appendicitis. Coll Antropol 2011;35:1299-302.

6. Al-Jaberi TM, Gharaibeh KI, Yaghan RJ. Torsion of abdominal appendages presenting with acute abdominal pain. Ann Saudi Med 2000;20:211-3.

7. Hasbahceci M, Erol C, Seker M. Epiploic appendagitis: Is there need for surgery to confirm diagnosis in spite of clinical and radiological findings? World J Surg 2012;36:441-6.

8. DuBose JJ, Jenkins DM, Quayle CM, Dress AL, Cotlar AM. Laparoscopic resection of infarcted appendices epiploicae of the colon. Curr Surg 2005;62:362-4.

9. Bandyopadhyay SK, Jain M, Khanna S, Sen B, Tantia O. Torsion of the epiploic appendix: An unusual cause of acute abdomen. J Minim Access Surg 2007;3:70-2.

10. Romaniuk CS, Simpkins KC. Case report: Pericolic abscess secondary to torsion of an appendix epiploica. Clin Radiol 1993;47:216-7.

11. Carmichael DH, Organ CH Jr. Epiploic disorders. Conditions of the epiploic appendages. Arch Surg 1985;120:1167-72.

12. Dockerty MB, Lynn TE, Waugh JM. A clinicopathologic study of the epiploic appendages. Surg Gynecol Obstet 1956;103:423-33.

13. Fieber SS, Forman J. Appendices epiploicae: Clinical and pathological considerations; report of three cases and statistical analysis on one hundred five cases. AMA Arch Surg 1953;66:329-38.

14. Ross JA. Vascular loops in the appendices epiploicae; their anatomy and surgical significance, with a review of the surgical pathology of appendices epiploicae. Br J Surg 1950;37:464-6.

How to cite this article: Singh R, Singh P. Torsion of Appendix Epiploicae as a Cause of Abdominal Pain in Postpartum Period - A Rare Case Report. Int J Dent Med Spec 2019;6(1):15-17.

Source of Support: None; Conflict of Interest: None 